the ESSDAI score. Work incapacity was assessed by the Work productivity and activity impairment for general health questionnaire (WPAI-GH) from which four dimensions can be calculated and expressed in percentages by the following scores: 1) percent work time missed due to health $=\mathrm{Q} 2 /(\mathrm{Q} 2+\mathrm{Q} 4)$ for those who were currently employed; 2) percent impairment while working due to health = Q5/10 for those who were currently employed and actually worked in the past seven days; 3) percent overall work impairment due to health Q2/(Q2 + Q4) + $((1-Q 2 /(Q 2+Q 4)) \times(Q 5 / 10))$ for those who were currently employed; 4) percent activity impairment due to health $\mathrm{Q} 6 / 10$ for all respondents.

Results: Eighty patients were randomly asked to fill out the questionnaire. Response rate was of $62.5 \%$. Total number of enrolled patients was 50 . The median age was 56.5 years $(\min =22, \max =60)$. Patients were mainly women with female to male ratio of 11.5:1. The median age of diagnosis was 50.5 years $(\min =18, \max =59)$. Mean duration of the disease was 6 years \pm 3.76 . Sicca syndrome was the most prevalent clinical feature affecting the eyes in $84 \%$ of the cases and the mouth in $90 \%$ of the cases. Arthralgia was present in $88 \%$ of the cases. $65.1 \%$ of patients had an active disease. Anti Ro antibodies were positive in $38 \%$, anti La in $28 \%$ and rheumatoid factor in $50 \%$ of cases. $36 \%$ of the patients were unemployed. Percentage of work time missed due to health for those who were employed in the past 7 days was $2.44 \%$ (Q1=0;Q2=5.26). Mean percentage of impairment while working due to health for those who were employed and actually worked in the past 7 days was $20.56 \pm 18.25 \%$. Percentage of overall work impairment due to health for those who were currently employed and actually worked was $25.87 \pm 19.58 \%$, and the percentage of overall activity impairment due to health for all respondents was $26.6 \pm 18.36 \%$. Analytic statistics showed no correlation between employment status and age, duration of disease, gender or seropositivity. However, all unemployed patients had ocular symptoms vs $75 \%$ of those employed ( $p$ value $=0.04$ ). The first dimension was correlated with the presence of dry mouth ( $p$ value $=0.07$ ) but with weak statistical significance. Second and third dimensions weren't associated to any general, clinical or laboratory feature. Fourth dimension was significantly correlated to the presence of dry eyes ( $p$ value $=0.019$ ) and gender ( $p$ value $=0.001$ ).

Conclusion: PSS is associated with high unemployment rates in Tunisia, high impairment rates while working and high rates of overall impairment. This high prevalence may be explained by gender and the presence of dry eyes and dry mouths. This work highlights the importance of managing sicca symptoms as they alter different aspects of quality of life like work.

References:

[1] Reilly MC, Zbrozek AS, Dukes EM. The validity and reproducibility of a work productivity and activity impairment instrument. PharmacoEconomics. nov 1993;4(5):353- 65.

[2] Mandl T, Jørgensen TS, Skougaard M, Olsson P, Kristensen L-E. Work Disability in Newly Diagnosed Patients with Primary Sjögren Syndrome. J Rheumatol. févr 2017;44(2):209-15.

Disclosure of Interests: : None declared

DOI: 10.1136/annrheumdis-2020-eular.5730

\section{AB0418 APPLICATION OF ACR (2012), ACR/EULAR (2016) AND RUSSIAN (2001) CRITERIA FOR PRIMARY SJÖGREN'S SYNDROME ON RUSSIAN COHORT OF PATIENTS}

J. Khvan $^{1}$, S. Palshina ${ }^{1}$, V. Vasiliev ${ }^{2}$, A. Torgashina ${ }^{1}$, E. Sokol ${ }^{1}$, B. Chaltcev ${ }^{1}$.

${ }^{1}$ V.A. Nasonova Research Institute of Rheumatology, Moscow, Russian

Federation: ${ }^{2}$ MEDSI, Moscow, Russian Federation

Background: Over the past few years new international criteria have been proposed for the classification of primary Sjögren's syndrome (pSS) from the American College of Rheumatology (ACR) in 2012 and the ACR with European League Against Rheumatism (ACR/EULAR) in 2016 [1, 2]. In real practice in Russia we use Russian criteria (2001).

Objectives: To estimate ACR (2012) and ACR/EULAR (2016) criteria in Russian cohort of patients with pSS patients fulfilling Russian criteria (2001).

Methods: From 2016 to 2019 we examined 110 patients (109 female, 1 male) with newly diagnosed pSS fulfilling Russian criteria with the mean age 50,2 \pm 14 years (min 18; $\max 82$ ). Russian criteria for pSS: I) keratoconjunctivitis sicca (stimulated Schirmer's test $<10 \mathrm{~mm} / 5 \mathrm{~min}$ or fluorescein staining of the cornea or tear break-up time $<10 \mathrm{sec}$ ); II) sialadenitis (sialectasia on parotid sialography (obligatory) +/- stimulated saliva flow test $<2,5 \mathrm{ml} / 5 \mathrm{~min}+/$ - labial salivary gland biopsy with focus score (FS) of $\geq 2$ foci $/ 4 \mathrm{~mm}^{2}$ ); III) positive antinuclear antibody (ANA) or positive ANA with rheumatoid factor (RF) or anti-SSA (anti-Ro) or/and SSB (anti-La). According it pSS is verified if the first two criteria and at least one of the immunological criteria are presented. We evaluated clinical, laboratory and instrumental features (table 1).
Table 1. Characteristics of Russian cohort of patients with primary Sjögren's syndrome $(n=110)$

\begin{tabular}{lc}
\hline Parameters & Patients (n / \%) \\
\hline ocular dryness & $76(69 \%)$ \\
oral dryness & $88(80 \%)$ \\
anti-SSA (anti-Ro) positive $(>25 \mathrm{IU} / \mathrm{ml})$ & $93(84.5 \%)$ \\
anti-SSB (anti-La) positive $(>25 \mathrm{IU} / \mathrm{ml})$ & $57(51.8 \%)$ \\
RF positive $>2 \mathrm{UNL}(>30 \mathrm{IU} / \mathrm{ml})$ & $68(61.8 \%)$ \\
ANA $\geq 1: 320$ & $110(100 \%)$ \\
(stimulated) Schirmer's test ( $\leq 5 \mathrm{~mm} / 5$ minutes) & $55(50 \%)$ \\
stimulated SFT $<2,5 \mathrm{ml} / 5 \mathrm{~min}$ & $77(70 \%)$ \\
OSS $\geq 5$ & $28(25.4 \%)$ \\
OSS $\geq 3$ & $43(39 \%)$ \\
FS $\geq 1$ foci/4 mm 2 & $99(90 \%)$ \\
Sialectasia on parotid sialography & $110(100 \%)$ \\
\end{tabular}

In our cohort according to Russian criteria (2001) 94 patients (86\%) fulfilled ACR (2012) criteria, $86(78 \%)$ - ACR/EULAR (2016) criteria.

Results: In our cohort, $20-30 \%$ of patients, according to Russian criteria did not complain of oral or ocular dryness. In $61 \%$ of patients, mild eye damage was detected $(O S S<3-5)$, and in half of the cases, the stimulated Schirmer's test was more than $5.0 \mathrm{~mm}$, but less than $10 \mathrm{~mm} / 5$ minutes, while $69 \%$ of patients complained of dry eyes. Most patients (84.5\%) had positive anti-Ro, just over half $(51.8 \%)$ had anti-La. All patients had sialectasia of various stages on parotid sialography. Less than $1 \mathrm{FS}$ was detected in $10 \%$ of patients.

Conclusion: Using Russian criteria (2001), we can identify pSS at an early stage. Our criteria inclusion complex examination in which an immunological sign must be present to confirm the diagnosis. Patients with pSS according to ACR (2012) and/or ACR/EULAR (2016) criteria seem to be diagnosed without specific antibodies and on the more progressive disease stages.

References:

[1] SC Shiboski, CH Shiboski, LA Criswell, AN Baer, S Challacombe, H Lanfranchi, M Schiødt, H Umehara, F Vivino, Y Zhao, Y Dong, D Greenspan, AM Heidenreich, P Helin, B Kirkham, K Kitagawa, G Larkin, M Li, T Lietman, J Lindegaard, N McNamara, K Sack, P Shirlaw, S Sugai, C Vollenweider, J Whitcher, A Wu, S Zhang, W Zhang, JS Greenspan, and TE Daniels for the Sjögren's International Collaborative Clinical Alliance (SICCA) Research Groups. American College of Rheumatology Classification Criteria for Sjögren's Syndrome: A Data-Driven, Expert Consensus Approach in the SICCA Cohort.

[2] Caroline H. Shiboski,1 Stephen C. Shiboski,1 Raphae `le Seror,2 Lindsey A. Criswell,1 Marc Labetoulle,2 Thomas M. Lietman,1 Astrid Rasmussen,3 Hal Scofield,4 Claudio Vitali, 5 Simon J. Bowman, 6 Xavier Mariette,2 and the International Sjogren's Syndrome Criteria Working Group. 2016 American College of Rheumatology/European League Against Rheumatism Classification Criteria for Primary Sjogren's Syndrome. ARTHRITIS \& RHEUMATOLOGY Vol. 00, No. 00, Month 2016, pp 00-00 DOI 10.1002/art.39859.

Disclosure of Interests: : None declared

DOI: 10.1136/annrheumdis-2020-eular.4686

\section{AB0419 FEVER (FMF) IN SYSTEMIC LUPUS ERYTHEMATOSUS (SLE) PATIENTS - A CROSS SECTIONAL STUDY}

T. Klein ${ }^{1}$, S. Tiosano ${ }^{1,2}$, A. Chohen ${ }^{3,4}$, H. Amital ${ }^{1,2} .{ }^{1} T e l$ Aviv University, Sackler Faculty of Medicine, Tel Aviv-Yafo, Israel; ${ }^{2}$ Sheba Medical Center, Medicine 'B', Tel-Hashomer, Ramat Gan, Israel; ${ }^{3} \mathrm{Clalit}$ Health Services, Quality Measurements and Research, Chief Physician's Office, Tel Aviv-Yafo, Israel; ${ }^{4}$ Ben Gurion University of the Negev, iaal Research Center for Family Medicine and Primary Care, Faculty of Health Sciences, Be'er Sheva, Israel

Background: Systemic Lupus Erythematosus (SLE) is a chronic autoimmune disease characterized by multisystem inflammatory lesions affecting many organ systems in the body. Familial Mediterranean fever (FMF) is an autosomal recessive disease of chronic autoimmune inflammation characterized by frequently relapsing self-limiting fever and inflammation that may be localized in peritoneum, pleura, joint or skin. ${ }^{1}$ Previous studies have described the similarity of clinical symptoms of FMF among SLE patients. However, the literature on this topic is inconsistent and based mostly on case reports. $^{2-4}$

Objectives: To examine the proportions of coexistence of FMF among SLE patients compared to the general population. We hypothesized that the proportion of FMF among SLE patients is higher than the general population.

Methods: This cross-sectional study used the Clalit Health Services database, the largest Health Maintenance Organization in Israel, serving 4,400,000 mem bers. SLE patients were compared to age- and sex-matched controls. Chi- was used for univariate analysis. 